\title{
Relationship Between Severity Levels of Diseases in Children with Maternal Anxiety at Pediatric Intensive Care Unit
}

\author{
Imelda*, Martira Maddeppungeng, Idham Jaya Ganda, Dasril Daud \\ Department of Pediatrics, Medical Faculty of Hasanuddin University, Makassar, South Sulawesi, Indonesia
}

Email address:

imeldabokko@gmail.com (Imelda),martira711@yahoo.com (M. Maddeppungeng),dhamjaya_spa@yahoo.co.id (I. J. Ganda), drdasri@gmail.com (D. Daud)

\section{To cite this article:}

Imelda, Martira Maddeppungeng, Idham Jaya Ganda, Dasril Daud. Relationship Between Severity Levels of Diseases in Children with Maternal Anxiety at Pediatric Intensive Care Unit. American Journal of Clinical and Experimental Medicine. Vol. 3, No. 3, 2015, pp. 94-98. doi: 10.11648/j.ajcem.20150303.14

\begin{abstract}
Background: PICU (pediatric intensive care unit) is child care units that require intensive surveillance and invasive action. A state of anxious disorder is characterized by feelings of fear which accompanied by somatic complaints shown with hyperactivities of autonomic nervous system and non-specific symptom and normal emotion. Objective: This study identified the factors associated with the occurrence of anxiety in mothers whose child was treated in a PICU suffered degrees of severity of disease. Methods: A cross-sectional studies have been conducted since April to September 2014 at Dr .Wahidin Sudirohusodo Hospital, Makassar. Samples were children aged 1 month to 18 years old who experienced the severity of the disease based on the PRISM III scores treated at PICU. Results: Of the 151 samples of children, there were 88 male and 63 female. Bivariate analyzes mothers who have children with PRISM III score $\geq 15$ had a greater occurrence frequency of severe anxiety disorders compared with mothers whose children have PRISM III score $<15$, with a value of $p=$ $0.000(p<0.01)$. There is a correlation between the PRISM III scores in children with maternal HARS scores, which is a higher PRISM III score will also make the HARS scores higher with $p<0.001$, correlation value of 0.296 . Conclusion: There is a correlation between PRISM III score in children and the score of HARS in the mother, which is the highest of PRISM III score, the HARS score will also be higher.
\end{abstract}

Keywords: PICU (Pediatric Intensive Care Unit), PRISM (Pediatric Risk of Mortality) III Score, HARS (Hamilton Anxiety Rating Scale) Score, Children

\section{Introduction}

PICU (pediatric intensive care unit) is child cares that require intensive monitoring and invasive action. Children in the intensive care unit are the ones who are in critical conditions, such as post-cardiac surgery, neurosurgery, postoperative gastrointestinal, respiratory failure, renal failure, liver failure, status epilepticus, and loss of consciousness. ${ }^{1}$ One of the important component of the assessment and quality improvement of care in the PICU was acuity of the scoring system that is able to assess objectively on morbidity, mortality, length of treatment, or costs for treatment. $^{2}$

Severity of the diseases greatly affects the risk of death, and the basic principles of assessing the severity of those diseases was applied as anticipation. Therefore, it is necessary to assess the severity of disease scores based on clinical condition or laboratory results such as PRISM III score. PRISM Scores (pediatric risk of mortality) III is a score used to predict the risks of death through physiological approach based on observation of the number and severity of physiological dysfunction. ${ }^{3}$

Mortality rates in the intensive care unit such as PICU are diverse $1.5 \%-8 \%{ }^{1}$ There are many factors could affect the risk of death of the patients hospitalized in the PICU which are the patient's age, the facilities of the treatment room, type of disease and the severity of disease suffered. The risk of death itself is a patients risk for mortality associated with the condition of the body and disease. ${ }^{3}$ Anxiety disorder is a condition characterized by feelings of fear accompanied by somatic complaints that are shown as hyperactivity of the autonomic nervous system and non-specific symptoms which 
are common and often is a normal emotion. ${ }^{4}$

Different people have different perspectives in the face of the same problem, and so are their responses. In addition to the intensive care room treatment, action or procedure that requires surgery is one of the factors that can aggravate mothers 'anxiety. Parent's anxiety problems, especially the mother, is important, because an illness child will also be able to feel the anxiety of their parents; therefore, the children could also become anxious that can aggravate their disease. ${ }^{5}$ Other impacts of excessive anxiety are the onset of panic and shock of the mother. She will also show a significant decline of her mental health if her child has a chronic disorder potential, thus it is important to do a research on the degree of severity of the disease in children associated with the level of parental anxiety. ${ }^{1}$

Study on maternal anxiety levels on mothers whose children were treated in the PICU has never been done in Makassar; therefore this research needs to be done in order to develop containment procedures of mother anxiety whose children suffered severe pain that could also have an impact on the patients care. The purpose of this study was to analyze the relationship between the severities of disease of the children who was being treated in intensive care (PICU) with the anxiety level of their mother.

\section{Materials and Methods}

This study was a cross-sectional study to assess the association between severity of disease and maternal anxiety levels. Method of sampling is by using the PRISM III scores for the child patients and HARS scores for their mother. PRISM III is a score of severity that allows assessing risk factors in patients admitted to the PICU. It is a simplification of the PSI (Physiological Stability Index) which the number of variables in less than 34 to 14, with a valuation ranges of 75 to 23 which includes four body systems.6PRISM III score can be used to assess the stability of the physiology of each day, the change in value reflects the state of the patient, and the increase in value indicates deterioration while impairment indicates an improvement. The PRISM score $<15$ means patient's risk of death is lower and score $\geq 15$ is patient's risk to a higher mortality associated with the state of the body and disease. The HARS score is to measure the degree of severity of anxiety disorders in patients' maternal.

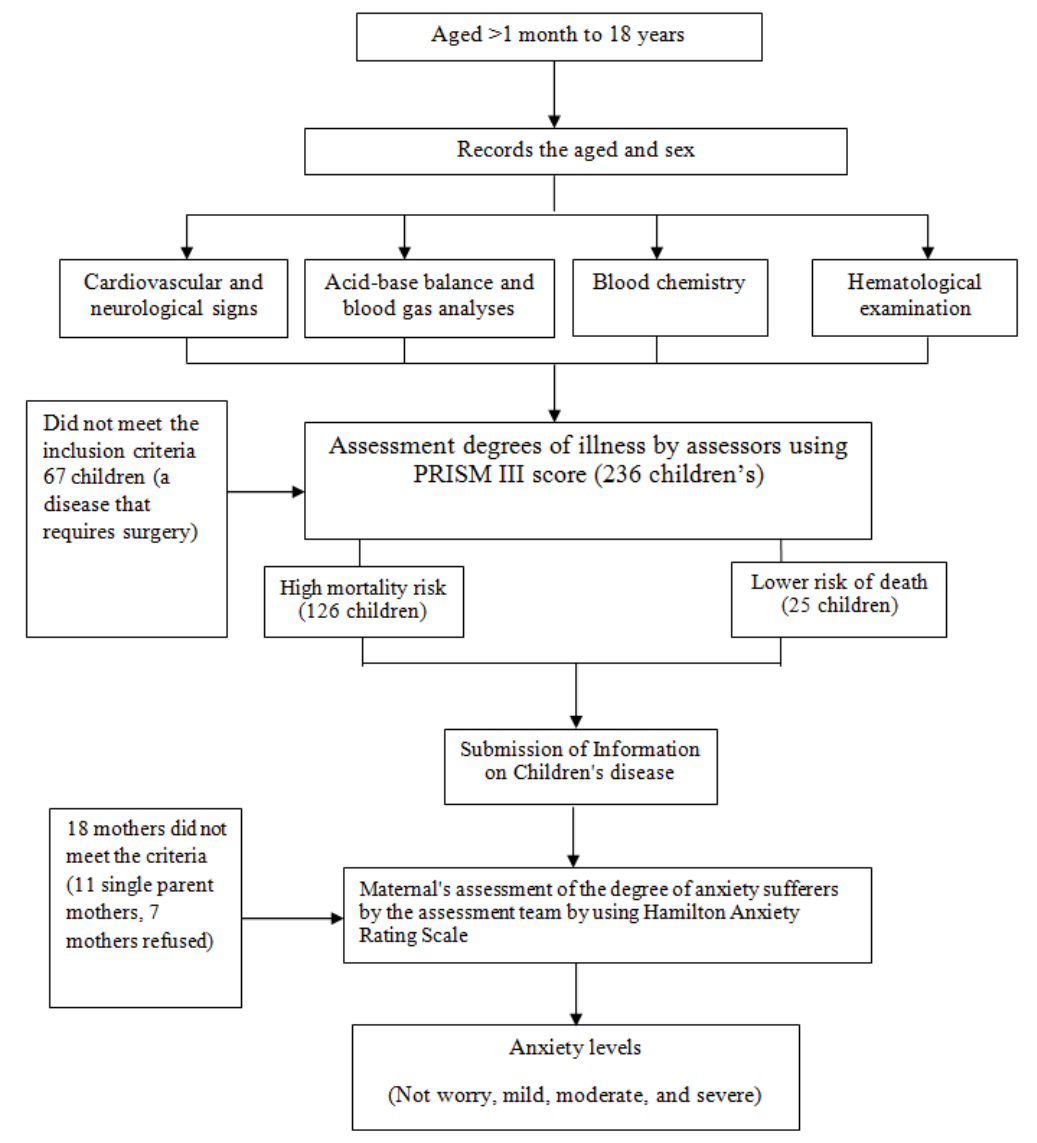

Figure 1. Study flow scheme.

This research was conducted at Dr. Wahidin Sudirohusodo hospital, Makassar from April to September 2014 for patients who are treated in the PICU. The study sample was taken from the entire population affordable that met the inclusion and exclusion criteria. The inclusion criteria are child aged
$<1$ month to 18 years, treated in PICU of Dr. Wahidin Sudirohusodo hospital, willing to participate in the study and signed an informed consent, and the maternal of the children cared for in the PICU. While, the exclusion criteria are maternal of patients experiencing psychiatric disorders, 
children are treated for in the PICU will be undertaken surgery, and women who become single parents.

The obtained data were grouped based on the purpose and their type and then analyzed with appropriate statistical methods, which is univariate and bivariate analyses consisted of X2 test (Chi square) or Fisher's exact test and Spearman correlation test. The patients are aged of $>1$ month to 18 years experienced the severe illness. This study was approved by the Ethics and Industry Research Committee of the hospital. Written informed consent was obtained from the patients' parents or legal guardian following full and detail explanation regarding the study's protocol. The study's working process is shown in the figure 1.

\section{Results}

The samples studied were 151 patients (children and their mother) that met the research criteria which consisted of 88 male and 63 female. The characteristics of the sample participated in the study are shown in table 1 . The results, aged $\leq 6$ years of $101(66.3 \%)$, children aged $>6$ years 50 (33.1\%). A group of children with PRISM III score $<15$ are $25(16.6 \%)$, children with PRISM III score $\geq 15$ are 126 (83.4\%). The order of the first child is as many as $73(48.3 \%)$, and which is not the first child are $78(51.7 \%)$. The number of children who is the only child are $50(33.1 \%)$ and the number of children more than one as many as $101(66.9 \%)$. The mother who was not scholars was 107 (70.9\%) and the scholars are $29.1 \%$ or 44 persons. The family income $\leq 150$ dollars as many as 28 people $(18.5 \%)$, while the ones who have income $>150$ dollars of $123(81.5 \%)$. Maternal age $<40$ years were $120(79.4 \%)$ and $\geq 40$ years are $31(20.6 \%)$.

Table 1. Characteristics of sample.

\begin{tabular}{ll}
\hline Characteristics & Total (N: \%) \\
\hline Sex & $88(58.3 \%)$ \\
Male & $63(41.7 \%)$ \\
Female & $101(66.3 \%)$ \\
Age & $50(33.1 \%)$ \\
$\leq 6$ Years & \\
$>6$ Years & $25(16.6 \%)$ \\
Group & $126(83.4 \%)$ \\
PRISM Score $<15$ & \\
PRISM Score $\geq 15$ & $73(48.3 \%)$ \\
Child Order & $78(51.7 \%)$ \\
$1^{\text {th }}$ & \\
$>1$ & $50(33.1 \%)$ \\
Among of Child & $101(66.9 \%)$ \\
1 Child & \\
$>1$ Child & $107(70.9 \%)$ \\
Education & $44(29.1 \%)$ \\
Nongraduate & \\
Graduate & $28(18.5 \%)$ \\
Family Income & $123(81.5 \%)$ \\
$<150$ dollars & \\
$>150$ dollars & $120(79.4 \%)$ \\
Age of mothers & $31(20.6 \%)$ \\
$<40$ years & \\
$\geq 40$ years &
\end{tabular}

Statistical analyses showed there is no significant difference between the age of the child, the order of children, number of children, family income to the level of maternal anxiety in hospitalized children in the PICU with $\mathrm{p}>0.005$. The results of this analysis are shown in table 2 .

Table 2. Relationship between sex, age, group of PRISM III Score, among of child, mother'seducation, family income, age of mother with anxiety of mother levels.

\begin{tabular}{|c|c|c|c|c|c|}
\hline \multirow[t]{2}{*}{ Characteristics } & \multirow[t]{2}{*}{ Total (N:\%) } & \multicolumn{2}{|c|}{ HARS score Anxiety levels } & \multirow[t]{2}{*}{ p value } & \multirow[t]{2}{*}{ OR value CI 95\% } \\
\hline & & Mild/Moderate & Severe & & \\
\hline \multicolumn{6}{|l|}{ Sex } \\
\hline Male & $88(58.3 \%)$ & $27(30.7 \%)$ & $61(69.3 \%)$ & 0.042 & 0.487 \\
\hline Female & $63(41.7 \%)$ & $30(47.6 \%)$ & $33(52.4 \%)$ & & $(0.24-0.95)$ \\
\hline \multicolumn{6}{|l|}{ Age } \\
\hline$\leq 6$ Years & $101(66.3 \%)$ & $37(36.6 \%)$ & $64(63.4 \%)$ & 0.72 & 0.867 \\
\hline$>6$ Years & $50(33.1 \%)$ & $20(40 \%)$ & $30(60 \%)$ & & $(0.42-1.73)$ \\
\hline PRISM Score $<15$ & $25(16.6 \%)$ & $19(70.6 \%)$ & $6(24.0 \%)$ & 0.000 & 7.33 \\
\hline PRISM Score $\geq 15$ & $126(83.4 \%)$ & $38(30.2 \%)$ & $88(69.8 \%)$ & & $(2.71-19.80)$ \\
\hline \multicolumn{6}{|l|}{ Child Order } \\
\hline $1^{\text {th }}$ & $73(48.3 \%)$ & $29(39.7 \%)$ & $44(60.3 \%)$ & 0.737 & 1.016 \\
\hline$>1^{\text {th }}$ & $78(51.7 \%)$ & $28(35.9 \%)$ & $50(64.1 \%)$ & & $(0.55-2.04)$ \\
\hline \multicolumn{6}{|l|}{ Among of Child } \\
\hline 1 Child & $50(33.1 \%)$ & $19(38 \%)$ & $31(62 \%)$ & 1.00 & 1.016 \\
\hline \multicolumn{6}{|l|}{ Mother's Education } \\
\hline Nonscholar & $107(70.9 \%)$ & $38(37.6 \%)$ & $59(55.1 \%)$ & 0.006 & 3.164 \\
\hline Scholar & $44(29.1 \%)$ & $48(44.9 \%)$ & $35(79.5 \%)$ & & $(1.386-7.22)$ \\
\hline \multicolumn{6}{|l|}{ Family Income } \\
\hline$<150$ dollars & $28(18.5 \%)$ & $10(35.7 \%)$ & $18(64.3 \%)$ & 1.00 & 0.89 \\
\hline$>150$ dollars & $123(81.5 \%)$ & $47(38.2 \%)$ & $76(61.8 \%)$ & & $(0.38-2.11)$ \\
\hline \multicolumn{6}{|l|}{ Age of mother } \\
\hline$<40$ years & $120(79.4 \%)$ & $44(36.7 \%)$ & $76(63.3 \%)$ & 0.679 & 0.80 \\
\hline$\geq 40$ years & $31(20.6 \%)$ & $13(41.9 \%)$ & $18(58.1 \%)$ & & $(0.359-1.79)$ \\
\hline
\end{tabular}

Chi Square Test; OR: Odds Ratio 
From the statistical analyses there are significant differences to the child sex and maternal education for the level of maternal anxiety with $\mathrm{p}<0.005$, but it became nonsignificant when it is tested against sex and education to the severity based on the PRISM III score, with $\mathrm{p}>0.005$. The results of the analyses statistics can be seen in table 3 .

Table 3. Relationship between age, mother's education with PRISM III Score.

\begin{tabular}{|c|c|c|c|c|c|}
\hline \multirow[t]{2}{*}{ Characteristic } & \multirow[t]{2}{*}{ Total (N:\%) } & \multicolumn{2}{|c|}{ PRISM III Score (patient's risk of death) } & \multirow[t]{2}{*}{$p$ Value } & \multirow[t]{2}{*}{ OR Value (CI95\%) } \\
\hline & & $<15$ & $\geq 15$ & & \\
\hline \multicolumn{6}{|l|}{ Sex } \\
\hline Male & $88(58.3 \%)$ & $11(12.5 \%)$ & $77(87.5 \%)$ & 0.125 & 0.5 \\
\hline Female & $63(41.7 \%)$ & $13(22.2 \%)$ & $49(77.8 \%)$ & & $(0.21-1.19)$ \\
\hline \multicolumn{6}{|l|}{ Mother Education } \\
\hline Nonscholar & $107(70.9 \%)$ & $18(16.8 \%)$ & $89(83.2 \%)$ & 1.000 & 1.069 \\
\hline Scholar & $44(29.1 \%)$ & $7(15.9 \%)$ & $37(84.1 \%)$ & & $(0.42-2.77)$ \\
\hline
\end{tabular}

OR: Odds Ratio

The results of the statistical analyses in table 4 shows that there is a correlation between the PRISM III scores with the HARS scores with $\mathrm{p}<0.001$.

Table 4. Correlation of PRISM III Score and HARS Score.

\begin{tabular}{lll}
\hline PRISM III Score & & HARS Score \\
\hline$r$ & 0.296 \\
$p$ & $<0.001$ \\
$n$ & 151 \\
\hline
\end{tabular}

Spearman correlation test

r: moment correlation coefficient

p: percentile

$\mathrm{n}$ : variables

\section{Discussion}

This study shows that there is a relationship between the severities of disease with PRISM III score to the maternal anxiety levels with HARS score. The sex frequency are 88 male $(58.3 \%)$ and 63 female $(41.7 \%)$, with the statistical test for sex on maternal anxiety levels indicated that there is a significant difference between the sex frequency on maternal anxiety levels with a value of $\mathrm{p}=0.034(\mathrm{p} \leq 0.05)$. The COR (crude odds ratio) value of 0.487 with $95 \%$ CI $(0.249$ to $0.952)$, this means that male who experienced the severity of disease is causing severe anxiety in the mother 0.48 times compared to the female. The frequency of children who experienced the severity of the disease based on the PRISM III score $<15$ was found less, which is 25 (16.6\%), and the group with the severity of disease with PRISM III score $\geq 15$ as many as $126(83.4 \%)$. Statistical analyses showed a highly significant difference between the groups of female who experience severe anxiety. The children experience the degree of severity of disease treated in intensive care by PRISM III score $<15$, compared with children who have the PRISM III score $\geq 15$, with $p<0.001$. This is consistent with the results of Kartikahadi research, who reported the mother anxiety factors whose child was treated in intensive care was significantly greater when compared with children treated at general ward.

In general, the value of PRISM III score experiencing severity were assessed by a high mortality risk is much greater than the value of the PRISM III scores in patients who have a low risk of death. This is similar with the research obtained by Board et al. who reported that the severity of disease experienced by the child has a positive relationship to the symptoms of stress suffered by his mother after 6 months is allowed to go home. ${ }^{8} \mathrm{~A}$ research has been reported that there was an increase in physiological distress when their children was diagnosed with severe pain. ${ }^{9}$ In contrast to research conducted by Youngblut et al. which states that the reaction of parents whose children are in care at PICU and stressors experienced by the parents did not correlate with the disease severity experienced by the child. ${ }^{10}$

Assessing on maternal education to test the mother levels of anxiety whose children was treated in intensive care by using HARS scores. Non scholar mother were 107 (70.9\%) compared with the scholars mother's educational levels as many as 44 people $(29.1 \%)$ to level of maternal anxiety. Statistical analyses showed a significant difference between the level of undergraduate education on maternal anxiety with $\mathrm{p}=0.006(\mathrm{p}<0.05)$. COR value $=3.164$ with $95 \% \mathrm{CI}$ values (1.386 to 7.224) which means that the frequency of mothers with undergraduate education level to experience severe anxiety is 3 times higher compared to the frequency of mothers who is non scholars. This is similar with the research conducted by Kasper et al. which states that parents need accurate information about the disease suffered by their children. ${ }^{11}$

Frequency of sex are tested by PRISM III scores in children and we found no significant difference between male and female that can lead to an increase in the PRISM III score, with $\mathrm{p}=0.113(\mathrm{p}>0.05)$. The result of sex statistical test on severity of disease showed no significant difference, this means that there is no effect of sex on the degree of severity of the disease in children admitted to intensive care (PICU). The group of mothers with undergraduate education level who have children with PRISM III scores $<15$ were 7 children (15.9\%) compared with children who have PRISM III score $\geq 15$ are 37 (84.1\%). Statistical analyses showed no significant difference on maternal education between both non graduate and undergraduate to the increase of PRISM III score, with $\mathrm{p}=0.550(\mathrm{p}>0.05)$. COR value $=1.069$ with $95 \%$ CI values ( 0.412 to 2.774$)$ which means that the odds ratio includes the number 1 indicates the mother's education is not 
a risk factor for the increase in PRISM III scores in children.

The correlation between HARS scores with PRISM III score was found significant with $\mathrm{p}<0.001$. The correlation value of 0.296 indicates that the direction of a positive correlation with the strength of a weak correlation. Statistical analyses showed that the highest of the PRISM III score experienced by the child, the higher the HARS score for the mother.

Based on the results, it can be concluded that the frequency of occurrence of severe anxiety in mothers was higher in mothers who have children with PRISM III score $\geq 15$ compared to children with PRISM III score $<15$. Based on these results it may be advisable to measure levels of maternal anxiety in hospitalized children in the PICU. It is advisable to use PSS: PICU (Parenteral Stressor Scale: Pediatric Intensive Care Unit) which is a questionnaire used to ask the parents whose children were treated in PICU. This questionnaire has been used internationally.

\section{References}

[1] Shudy M., de Almeida ML., Lo S., Landon C., Groft S., Jenkins TL. Impact of pediatric critical illness and injury on families: a systematic literature review. Pediatrics. 2006; 118: S203-18

[2] Marlina L., Hudaya D., Garna H. Comparison of use Pediatric Index of Mortality 2 (PIM2) and Pediatric Logistic Organ Dysfunction score (PELOD), to predict the death of critically illness in children. Sari Pediatri. Jakarta. 2008; 10: 4
[3] Dewi, NE. Validity scores "Pediatric Risk of Mortality" as a detection tool of mortality risk pediatric emergency patients. Thesis of the Medical Education Program Specialist-1, Faculty of Medicine, University of Diponegoro, Semarang. 1998; 31-60

[4] Aldridge MD. Decreasing parenteral stress in the Pediatric Intensive Care Unit. Crit Care Nurse. 2005; 25:40-50

[5] Saied H. Stress, coping, social support and adjustment among families of CHD in children in PICU after heart surgery. Case Western Reserve University. 2013; 100-105

[6] BhadoriaP, Bhagwat AG. Severity scoring system in Paediatric Intensive Care units. 2008; 663-675.

[7] Kartikahadi, Lie. Comparison of maternal anxiety scores in pediatricintensive care unit and general ward parents. Paediatrica Indonesiana. 2012; 52: 95-8

[8] Board R., Ryan-Wenger N. Long-term effects of pediatric intensive care unit hospitalization on families with young children. Heart Lung. 2002; 31:53-66

[9] Tomlinson PS, Harbaugh BL, Kotchevar J, Swanson L. Caregiver mental health and family health outcomes following critical hospitalization of a child. Issues Ment Health Nurs. 1995; 16:533-545

[10] Youngblut JM, Shiao SP. Child and family reactions during and after pediatric ICU hospitalization: a pilot study. HeartLung. 1993; 22:46-54

[11] Kasper J., Nyamathi A.Parents of children in the pediatric intensive care unit: what are their needs?.Heart Lung.1998; $17: 574-581$ 